\title{
Correlation between maximum voluntary contraction and endurance measured by digital palpation and manometry: An observational study
}

Fátima Faní Fitz ${ }^{1 *}$, Liliana Stüpp ${ }^{2}$, Thaís Fonseca Costa ${ }^{3}$, Marair Gracio Ferreira Sartori ${ }^{4}$, Manoel João Batista Castello Girão ${ }^{4}$, Rodrigo Aquino Castro ${ }^{4}$

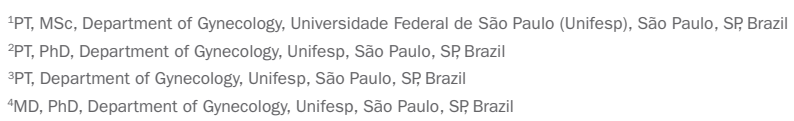

Study conducted at Departamento de Ginecologia, Universidade Federal de São Paulo (Unifesp), São Paulo, SP, Brazil

Article received: $6 / 29 / 2015$ Accepted for publication: $7 / 6 / 2015$

*Correspondence: Departamento de Ginecologia Address: Rua Napoleão de Barros, 608 São Paulo, SP - Brazil Postal code: 04024-002 fanifitz@yahoo.com.br

http://dx.doi.org/10.1590/1806-9282.62.07.635

Financial support: This study was funded by the National Council for Scientific and Technological Development (CNPq) research foundation, grant $n^{\circ} 140190 / 2013-9$

\section{SUMmarY}

Introduction: Digital palpation and manometry are methods that can provide information regarding maximum voluntary contraction (MVC) and endurance of the pelvic floor muscles (PFM), and a strong correlation between these variables can be expected.

Objective: To investigate the correlation between MVC and endurance, measured by digital palpation and manometry.

Method: Forty-two women, with mean age of 58.1 years $( \pm 10.2)$, and predominant symptoms of stress urinary incontinence (SUI), were included. Examination was firstly conducted by digital palpation and subsequently using a Peritron manometer. MVC was measured using a 0-5 score, based on the Oxford Grading Scale. Endurance was assessed based on the PERFECT scheme.

Results: We found a significant positive correlation between the MVC measured by digital palpation and the peak manometric pressure $(\mathrm{r}=0.579, \mathrm{p}<0.001)$, and between the measurements of the endurance by Peritron manometer and the PERFECT assessment scheme $(r=0.559, \mathrm{p}<0.001)$.

Conclusion: Our results revealed a positive and significant correlation between the capacity and maintenance of PFM contraction using digital and manometer evaluations in women with predominant symptoms of SUI.

Keywords: pelvic floor, stress urinary incontinence, palpation/methods, vaginal squeeze pressure, manometry.

\section{INTRODUCTION}

According to the International Continence Society (ICS), pelvic floor muscle (PFM) function is defined by the ability to perform a normal or strong voluntary contraction, with the presence of an involuntary contraction, resulting in a "circular closing of the vagina, the urethra, and the anus" and in a "cranioventral movement of the perineum and upward movement of the pelvic organs."

PFM training should be recommended as a first-line conservative management in the treatment of urinary incontinence, ${ }^{2,3}$ as demonstrated by numerous randomized controlled trials. ${ }^{4-7}$ The success of treatment with exercises is dependent on the achievement of strength and endurance, which consequently leads to improvement of the PFM function. Evaluation of PFM function is a difficult task, as there is no consensus regarding the best method to evaluate or control the effects of PFM training. There are various methods to verify and quantify PFM function supported by the ICS, which include visual inspection, intravaginal palpation, electromyography, pressure measurements, and imaging methods, such as ultrasound, magnetic resonance imaging (MRI), and video urodynamics. Visual inspection and digital palpation are the most common methods used by physiotherapists. ${ }^{1,8}$

The vaginal palpation was first described by Kegel, ${ }^{9}$ who performed it to teach patients how to contract the 
muscles, classifying muscle contraction subjectively as correct or incorrect. Currently, digital palpation is still considered an essential part of the PFM examination, and has become widespread due to its low cost, and also because it is well accepted by the patients. The evaluation of muscle strength and endurance provides information about the severity of muscle weakness and forms the basis for patient-specific exercise programs. ${ }^{10}$

In recent years, different methods have been developed to evaluate PFM function quantitatively. ${ }^{11,12}$ The measurement of vaginal pressure has been considered a reproducible method. ${ }^{13,14}$ However, practitioners should be aware that increased intra-abdominal pressure might occur during the evaluation and influence the results. Thus, this method should not be used alone. ${ }^{13}$

Considering that both digital and manometric methods are able to provide information with respect to maximal voluntary contraction (MVC) and endurance, a strong correlation between these variables can be expected. Thus, the aim of this study was to investigate this correlation, as measured by digital palpation and manometry.

\section{Method}

\section{Study design}

We present an observational and correlational study assessing the correlation between MVC and endurance measured by digital palpation and manometry.

Women admitted with untreated mixed stress urinary incontinence (SUI) and more than $2 \mathrm{~g}$ of leakage, as proven by a pad test with a standardized bladder volume, ${ }^{15}$ were enrolled in this trial at the Division of Urogynecology and Reconstructive Pelvic Surgery of the Universidade Federal de São Paulo (Unifesp), Brazil. This study was approved by the Review Board Committee of this institution (CEP 1981/10). Each participant provided a written informed consent.

Patients with less than $2 \mathrm{~g}$ of urinary leakage (by pad test) and/or inability to contract the PFM were not included. Potential subjects were excluded if they had chronic degenerative diseases affecting the muscular and nerve tissues, diabetes, cerebrovascular diseases or overt neurological conditions, or autoimmune connective tissue disorders; if they were pregnant; or if they had previously undergone pelvic floor re-education programs and/ or pelvic floor surgery.

To ascertain adequate PFM contraction, each volunteer was assessed by inspection and digital vaginal palpation to observe a lift of the pelvic floor in a superior, anterior direction and a constriction around the urethra, vagina, and rectum while in supine position..$^{16}$ The patients were requested to "lift and squeeze the PFM as hard as possible." The co-contraction of the gluteal, hip adductor and rectus abdominal muscles was discouraged.

Once enrolled by a physiotherapist investigator, each subject completed a questionnaire designed to collect demographic characteristics such as age, body mass index (BMI), parity, and hormonal status.

\section{Procedure}

The assessments of the MVC and muscle endurance by digital palpation and vaginal squeeze pressure measurement were conducted by a physiotherapist specialized in PFM rehabilitation. Digital and vaginal pressure evaluations were carried out randomly, on the same day, with a 1-hour interval between measurements. The sequence of measurements was MVC followed by endurance. Three consecutive muscle contractions were recorded, with a 10 -second interval between efforts, ${ }^{17}$ and the best of three was registered. ${ }^{18}$

One researcher (T.F.) was responsible for evaluating all patients and did not have knowledge about the analysis of correlation between the measurements. This researcher was instructed to use the same verbal command in all measurements. These results are part of a larger study involving pre- and post-physical therapy treatment. Subsequently, the main investigator (F.F.) performed the analysis of data. Both researchers are physiotherapists specialized in pelvic floor dysfunctions.

\section{Digital palpation}

Digital palpation was used to assess PFM strength and endurance. To quantify muscle strength, a score from 0-5 was given based on the previously validated Oxford Grading Scale (Table 1). ${ }^{19}$ Endurance was recorded via the PERFECT assessment scheme. ${ }^{20}$ Endurance was expressed as the length of time, up to 10 seconds, that an MVC could be sustained. Thus, the contraction was registered until the muscle began to fatigue.

TABLE 1 Assessment of PFM activity according to the Oxford Grading Scale modified by Laycock.

\section{Oxford Grading Scale by Laycock}

\begin{tabular}{ll}
\hline 0 & No muscle activity \\
\hline 1 & Minor muscle "flicker" \\
\hline 2 & Weak muscle activity without a circular contraction \\
\hline 3 & Moderate muscle contraction \\
\hline 4 & Good muscle contraction \\
\hline 5 & Strong muscle contraction
\end{tabular}




\section{Vaginal squeeze pressure measurement}

The vaginal squeeze pressure measurement was performed using a Peritron manometer (Cardio Design ${ }^{\mathrm{TM}}$, Victoria, Australia). This equipment has a conical vaginal catheter, with diameter and length of $26 \mathrm{~mm}$ and $108 \mathrm{~mm}$, respectively. The vaginal catheter was connected to a handheld microprocessor with latex tubing, allowing the transmission of pressure $\left(\mathrm{cmH}_{2} \mathrm{O}\right)$ when the insert is compressed by external pressure. The catheter was covered with a sterile latex sleeve for each patient. The vaginal catheter was inserted into the vaginal canal until the full extent of the compressible portion of the device was above the level of the hymenal ring. The baseline pressure reading was recorded after the catheter was inflated to $100 \mathrm{cmH}_{2} \mathrm{O}$, and then the device was reset.

\section{Statistical analysis}

SPSS (Statistical Package for Social Sciences, IBM Company, Chicago, USA) version 21.0 was chosen for the statistical analyses. Spearman's correlation test was used to correlate the values obtained using Peritron manometer, the modified Oxford Grading Scale and the PERFECT assessment scheme. P-values were set to $<0.05$ to indicate statistical significance. The power of the relationship between the variables was classified as high reliability $(0.80$ to 1.00$)$, moderate reliability ( 0.60 to 0.80 ), and questionable reliability $(<0.59)$, according to Richman et al. ${ }^{21}$

\section{Results}

\section{Recruitment, retention, and compliance}

Forty-six (46) women diagnosed with mixed and SUI in the period from March 2011 to October 2013 were included in the study. Four women were excluded from the study because they were unable to perform a proper PFM contraction. The remaining 42 participants underwent digital assessment and vaginal pressure measurement. None of the women declined to participate in this study.

\section{Baseline characteristics}

The mean age was 58.1 years ( \pm 10.2 years), BMI was 29.3 $\mathrm{kg} / \mathrm{m}^{2}\left( \pm 5.8 \mathrm{~kg} / \mathrm{m}^{2}\right)$, and the mean parity was $3.3( \pm 2.6)$. Thirty-one (73.8\%) women were menopaused. The mean of urinary leakage registered in pad test was $18.1 \mathrm{~g}( \pm 24.8 \mathrm{~g})$.

\section{Digital and vaginal pressure measurements}

MVC was classified based on the Oxford Grading Scale system as flicker $(n=2)$, weak $(n=20)$, moderate $(n=13)$, good $(n=3)$, and strong $(n=4)$. The vaginal pressure measurements revealed an average score of $22.0 \mathrm{cmH}_{2} \mathrm{O}( \pm 15.0$ $\mathrm{cmH}_{2} \mathrm{O}$ ), and the Oxford Grading Scale revealed an aver- age score of $2.6( \pm 1.0)$. There was a significant positive correlation between MVC according to the Oxford Grading Scale score and the peak pressure of manometry $(\mathrm{r}=0.579, \mathrm{p}<0.001)$ (Figure 1).

Measurements of endurance by Peritron manometer and the PERFECT assessment scheme yielded an average score of 3.8 seconds ( \pm 1.6 seconds) and 3.0 seconds $( \pm 1.4$ seconds), respectively. There was a significant positive correlation between these variables $(r=0.559, \mathrm{p}<0.001)$ (Figure 2$)$.

\section{Discussion}

Ability to contract the PFM has been addressed by many studies. Instruction is mandatory and should be performed by verbal commands, followed by digital palpation and/ or manometry. ${ }^{5,6,22}$ Digital palpation is not considered a reproducible or valid method for measuring the PFM strength, ${ }^{17}$ and peak pressure of manometry should not be used alone. ${ }^{16}$ Therefore, it is noteworthy for clinical practice that the combined use of both methods has a good correlation.

A recent prospective cohort study was conducted to verify the correlation between PFM function as determined by the Oxford Grading Scale and perineometry in pregnant and postpartum women. The authors found a positive correlation, indicating that both vaginal palpation and perineometry are valid and reliable methods for measure the PFM function. ${ }^{12}$ Accordingly, Ferreira et al. reported good inter-observer reliability for the modified Oxford Grading Scale and moderate reliability for manometry. ${ }^{23}$

Frawley et al. investigated the intra-observer reliability of bidigital evaluation and vaginal manometry, as well as resistance in different positions. The authors stated that both methods are reliable for quantifying MVC in standing and supine positions. Additionally, manometry is more reliable than vaginal palpation. ${ }^{24}$

Two studies investigated the inter-rater reliability of other palpation scoring systems, with squeeze pressures ranging from moderate to high ( $\mathrm{r}=0.60$ to $\mathrm{r}=0.90) \cdot{ }^{25,26}$ Our findings suggest that the correlation coefficient is questionable with respect to MVC $(r=0.57)$ and muscle endurance $(\mathrm{r}=0.55)$. Likewise, previous studies have shown weak inter-rater reliability for the Oxford Grading Scale using Cohen's Kappa $(0.37)^{17}$ and moderate inter-rater reliability for the Peritron manometer. ${ }^{23} \mathrm{Da}$ Roza et al. have also found a moderate correlation between digital evaluation and manometry $(r=0.65)$ in nulliparous athlete students. ${ }^{27}$

Ultrasound imaging is considered a responsive and reliable method to assess the PFM movement during contraction. ${ }^{28}$ Dietz et al. correlated the cranioventral displacement on ultrasound with vaginal palpation and 


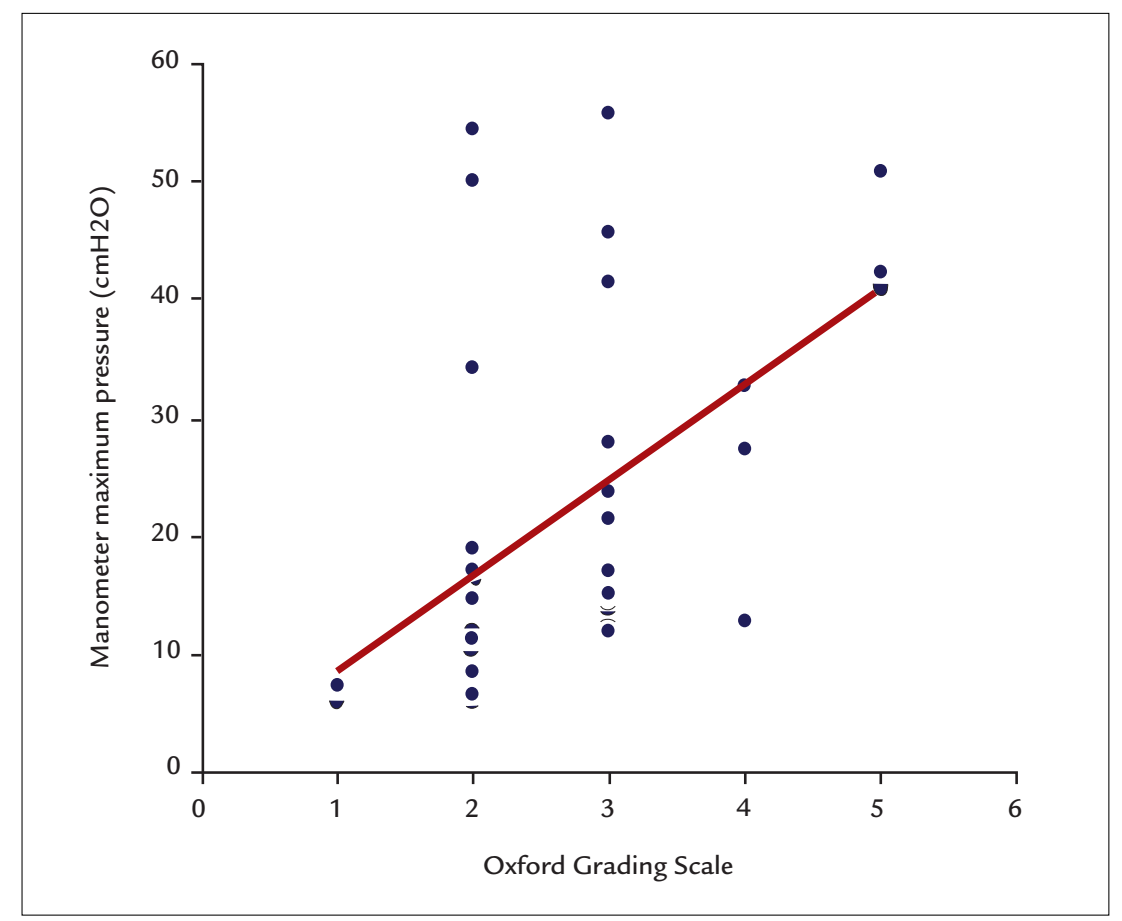

FIGURE 1 Maximum voluntary contraction measured by the Oxford Grading Scale.

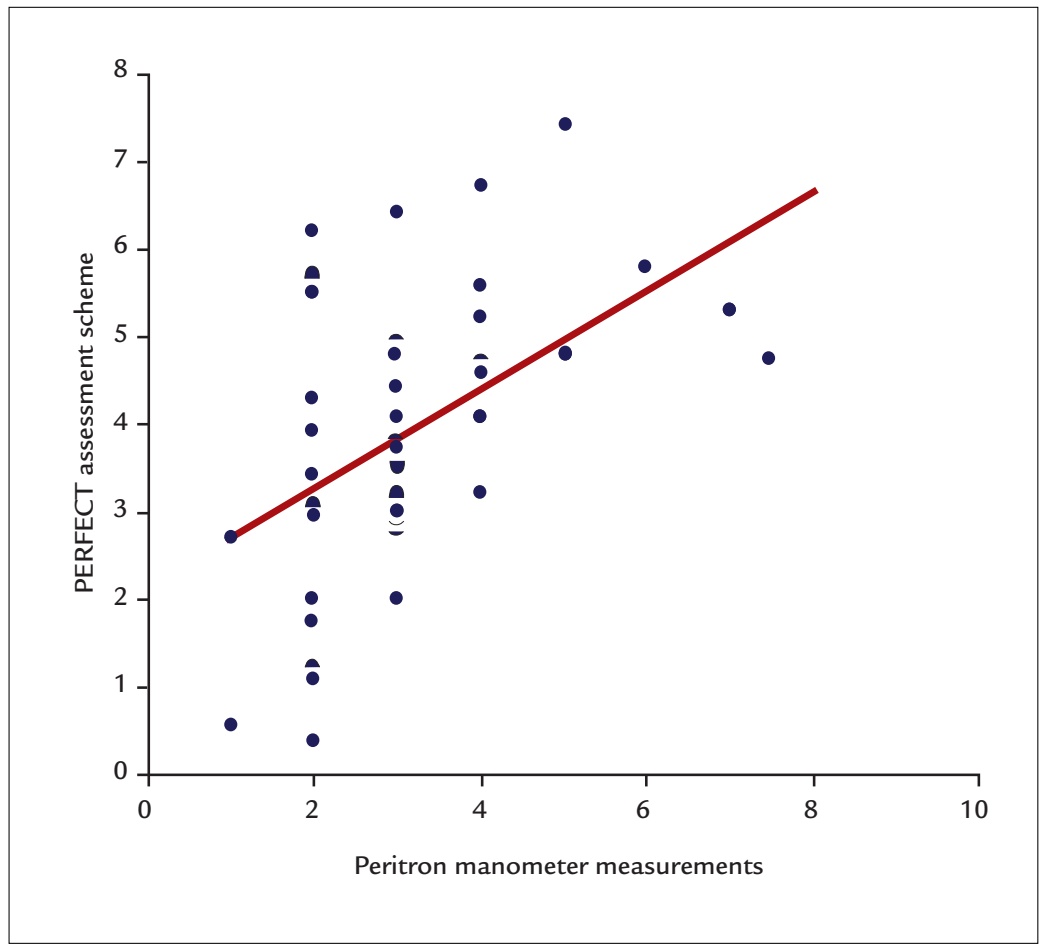

FIGURE 2 PERFECT assessment scheme vs. Peritron manometer - endurance measurements. 
perineometry and found a highly significant correlation $\left(r=0.62\right.$ and $r=0.52$, respectively)..$^{29}$ Another study found a moderate association between ultrasound and perineometry in women with pelvic organ prolapse. ${ }^{30}$ However, the perineal ultrasound does not offer the possibility of quantifying PFM contraction. ${ }^{31}$

Dietz et al. performed a comparative study of bidigital palpation and 4D ultrasound to evaluate trauma in the levator ani muscle. The authors found poor agreement between the two methods and concluded that imaging has a higher reliability than vaginal palpation, even when performed by a trained and experienced physiotherapist. ${ }^{32}$

Further studies using perineometry to evaluate the PFM are required to avoid capturing the action of the other muscle groups that form the wall of the abdominopelvic cavity, ${ }^{33}$ because an increase in abdominal pressure will affect the urethral, vaginal and rectal pressures. ${ }^{34}$ However, Perschers et al. assessed the effect of contraction of the abdominal muscles concomitant with the pelvic floor and reported no significant increase in readings during digital palpation, perineometry, electromyography or ultrasound. ${ }^{31}$ In the present study, all women who were able to contract the PFM correctly were included, and only contractions with a simultaneous inward movement of the catheter or perineum were considered valid. ${ }^{13}$

Measurements of vaginal squeeze pressure depend on the vaginal probe that is used. Differences may arise due to the length and diameter of the probes, straining, a learning effect or different placement of the devices inside the vagina. ${ }^{17}$ Bo et al. found mean values of maximum squeeze pressure of $19.7 \mathrm{cmH}_{2} \mathrm{O}$ and $36.5 \mathrm{cmH}_{2} \mathrm{O}$ after evaluating with different types of manometers $(\mathrm{p}<0.01) .{ }^{35}$ Some factors, such as age, BMI, size of genital hiatus and parity, must be taken into consideration to assess the reliability of the evaluation of PFM by manometry. ${ }^{36}$ Nevertheless, Hundley et al. reported that none of these variables influence the examination. ${ }^{33}$ Brækken et al. reported that thicker muscles and a smaller levator hiatus were associated with greater strength and muscular endurance; additionally, a smaller levator hiatus was associated with higher vaginal resting pressure. ${ }^{30}$

The strength of the present study was the evaluation of muscle endurance, which is recognized but not commonly reported in the literature. Endurance reveals the severity of muscle weakness and is recommended to be included in all PFM training prescriptions. ${ }^{36}$ The weakness of this study was the limited sample size.

In our study, the correlation found could be considered questionable because these methods are grounded on different principles. Vaginal pressure detects the compres- sion of the PFM, while the Oxford Scale analyzes the compression and elevation of these muscles. In our opinion, the evaluation of compression and elevation performed separately should be considered and investigated.

We have demonstrated the importance of pelvic floor bidigital evaluation and manometry in providing various data that can enrich existing clinical and scientific knowledge. These methods have limitations, and their reliability in the academic field is still questioned. The training and experience of the evaluator are of extreme importance, as these metrics determine how reliable and realistic the results are. Our findings suggest there is still a gap in the existing information regarding the relationships among these variables, particularly pelvic muscle endurance. We recommend further studies with strong methodological design should be performed.

\section{Conclusion}

Our results revealed a positive and significant correlation between the capacity and maintenance of PFM contraction using digital and manometer evaluations in women with predominant symptoms of SUI. However, this correlation was classified as questionable.

\section{ACKNOWLEDGMENTS}

This study was funded by the National Council for Scientific and Technological Development (CNPq) research foundation, grant n. 140190/2013-9.

\section{Resumo}

Correlação entre contração voluntária máxima e endurance avaliados por palpação digital e manometria: um estudo observacional

Introdução: a palpação digital e a manometria são métodos capazes de fornecer informações sobre contração voluntária máxima (CVM) e endurance da musculatura do assoalho pélvico (MAP), e pode-se esperar uma forte correlação entre essas variáveis.

Objetivo: investigar a correlação entre CVM e endurance, avaliados por palpação digital e manometria.

Método: incluíram-se 42 mulheres, com idade média de 58,1 anos $( \pm 10,2)$ e sintomas predominantes de incontinência urinária de esforço (IUE). Realizou-se primeiramente o exame digital, seguido pela manometria (Peritron $($ )). Mensuraram-se a CVM de acordo com a escala de Oxford (0-5 pontos) e o endurance pelo esquema PERFECT.

Resultados: encontrou-se correlação positiva entre CVM mensurada por palpação digital e pressão mano- 
métrica de pico $(r=0,579 ; \mathrm{p}<0,001)$, e entre as medições do endurance avaliado pelo Peritron e o esquema PERFECT $(\mathrm{r}=0,559 ; \mathrm{p}<0,001)$.

Conclusão: os resultados revelaram correlação positiva e significativa entre a capacidade e a manutenção de contração dos MAP por meio das avaliações digital e manométrica em mulheres com IUE.

Palavras-chave: assoalho pélvico, incontinência urinária de esforço, palpação/métodos, pressão de contração vaginal, manometria.

\section{RefEREnCES}

1. Messelink B, Benson T, Berghmans B, Bo K, Corcos J, Fowler C, et al. Standardization of terminology of pelvic floor muscle function and dysfunction: report from the pelvic floor clinical assessment group of the international continence society. Neurourol Urodyn. 2005; 24(4):374-80.

2. Fitz FF, Resende AP, Stüpp L, Sartori MG, Girão MJ, Castro RA. Biofeedback for the treatment of female pelvic floor muscle dysfunction: a systematic review and meta-analysis. Int Urogynecol J. 2012; 23(11):1495-516.

3. Hay-Smith E, Bø K, Berghmans LC, Hendriks HJ, de Bie RA, van Waalwijk van Doorn ES. WITHDRAWN: Pelvic floor muscle training for urinary incontinence in women. Cochrane Database Syst Rev. 2013; (1):CD001407.

4. Berghmans LC, Frederiks CM, de Bie RA, Weil EH, Smeets LW, van Waalwijk van Doorn ES, et al. Efficacy of biofeedback, when included with pelvic floor muscle exercise treatment, for genuine stress incontinence. Neurourol Urodyn. 1996; 15(1):37-52.

5. Mørkved S, Bø K, Fjørtoft T. Effect of adding biofeedback to pelvic floor muscle training to treat urodynamic stress incontinence. Obstet Gynecol. 2002; 100(4):730-9.

6. Bø K, Talseth T, Holme I. Single blind, randomised controlled trial of pelvic floor exercises, electrical stimulation, vaginal cones, and no treatment in management of genuine stress incontinence in women. BMJ. 1999; 318(7182): 487-93.

7. Castro RA, Arruda RM, Zanetti MRD, Santos PD, Sartori MG, Girão MJ. Single-blind, randomized, controlled trial of pelvic floor muscle training, electrical stimulation, vaginal cones, and no active treatment in the management of stress urinary incontinence. Clinics (São Paulo). 2008; 63(4):465-72

8. Talasz H, Gosch M, Enzelsberger H, Rhomberg HP. [Female geriatric patients with urinary incontinence symptoms and their control over pelvic floor muscles]. Z Gerontol Geriatr. 2005; 38(6):424-30.

9. Kegel AH. Progressive resistance exercise in the functional restoration of the perineal muscles. Am J Obstet Gynecol. 1948; 56(2):238-49.

10. Bø K, Scherburn M. Evaluation of female pelvic floor muscle function and strength. Phys Ther. 2005; 85(3):269-82.

11. Barbosa PB, Franco MM, Souza F de O, Antônio FI, Montezuma T, Ferreira $\mathrm{CH}$. Comparison between measurements obtained with three different perineometers. Clinics (São Paulo). 2009; 64(6):527-33.

12. Riesco ML, Caroci AS, de Oliveira SM, Lopes MH. Perineal muscle strength during pregnancy and postpartum: the correlation between perineometry and digital vaginal palpation. Rev Lat Am Enfermagem. 2010; 18(6):1138-44.

13. Bø K, Kvarstein B, Hagen R, Larsen S. Pelvic floor muscle exercise for the treatment of female stress urinary incontinence: I. Reliability of vaginal pressure measurements of pelvic floor muscle strength. Nerourol Urodyn. 1990; 9(5):471-7.

14. Dougherty MC, Abrams R, McKey PL. An instrument to assess the dynamic characteristics of the circumvaginal musculature. Nurs Res. 1986; 35(4):202-6.

15. Lose G, Rosenkilde P, Gammelgaard J, Schroeder T. Pad-weighing test performed with standardized bladder volume. Urology. 1988; 32(1):78-80.
16. Bø K, Kvarstein B, Hagen R, Larsen S. Pelvic floor muscle exercise for the treatment of female stress urinary incontinence: II. Validity of vaginal pressure measurements of pelvic floor muscle strength and the necessity of supplementary methods for control of correct contraction. Neurourol Urodyn. 1990; 9(5):479-87.

17. Bø K, Finckenhagen HB. Vaginal palpation of pelvic floor muscle strength: inter-test reproducibility and comparison between palpation and vaginal squeeze pressure. Acta Obstet Gynecol Scand. 2001; 80(10):883-7.

18. Grape HH, Dedering A, Jonasson AF. Retest reliability of surface electromyography on the pelvic floor muscles. Neurourol Urodyn. 2009; 28(5):395-9.

19. Laycock J. Clinical evaluation of the pelvic floor. In: Schussler B, Laycock J, Norton P, Stanton S, editors. Pelvic floor re-education principles and practice. London: Springer; 2002. p. 42-8

20. Laycock J, Jerwood D. Pelvic floor muscle assessment: the PERFECT scheme. Physiotherapy. 2001; 87(12):631-42.

21. Richman J, Mackrides L, Prince B. Research methodology and statistics. Part 3: measurement procedures in research. Physiother Can. 1980; 32:253-7.

22. Rett MT, Simões JA, Herrmann V, Pinto CL, Marques AA, Morais SS Management of stress urinary incontinence with surface electromyographyassisted biofeedback in women of reproductive age. Phys Ther. 2007; $87(2): 136-42$

23. Ferreira CH, Barbosa PB, de Oliveira Souza F, Antônio FI, Franco MM, Bø K. Inter-rater reliability study of the modified Oxford Grading Scale and the Peritron manometer. Physiotherapy. 2011; 97(2):132-8.

24. Frawley HC, Galea MP, Phillips BA, Sherburn M, Bø K. Reliability of pelvic floor muscle strength assessment using different test positions and tools. Neurourol Urodyn. 2006; 25(3):236-42.

25. Brink CA, Wells TJ, Sampselle CM, Taillie ER, Mayer R. A digital test for pelvic muscle strength in women with urinary incontinence. Nurs Res. 1994; 43(6):352-6.

26. Hove MCPS, Pool-Goudzwaard AL, Eijkemans MJC, Steegers-Theunissen RP, Burger CW, Vierhout ME. Face validity and reliability of the first digital assessment scheme of pelvic floor muscle function conform the new standardization terminology of the International Continence Society. Neurourol Urodyn. 2009; 28(4):295-300.

27. Da Roza T, Mascarenhas T, Araujo M, Trindade V, Jorge RN. Oxford Grading Scale vs manometer for assessment of pelvic floor strength in nulliparous sports students. Physiotherapy. 2013; 99(3):207-11.

28. Dietz HP. Ultrasound in the assessment of pelvic floor muscle and pelvic organ descent. In: Bø K, Berghmans B, Morkved S, Van Kampen M. Evidence based physical therapy for the pelvic floor. Amsterdam: Elsevier; 2007. p. 81-92.

29. Dietz HP, Jarvis SK, Vancaillie TG. The assessment of levator muscle strength: a validation of three ultrasound techniques. Int Urogynecol J Pelvic Floor Dysfunct. 2002; 13(3):156-9.

30. Brækken IH, Majida M, Engh ME, Bø K. Are pelvic floor muscle thickness and size of levator hiatus associated with pelvic floor muscle strength, endurance and vaginal resting pressure in women with pelvic organ prolapse stages I-III? A Cross Sectional 3D Ultrasound Study. Neurourol Urodyn. 2014; 33(1):115-20.

31. Peschers UM, Gingelmaier A, Jundt K, Leib B, Dimpfl T. Evaluation of pelvic floor muscle strength using four different techniques. Int Urogynecol J Pelvic Floor Dysfunct. 2001; 12(1):27-30

32. Dietz HP, Hyland G, Hay-Smith J. The assessment of levator trauma: a comparison between palpation and 4D pelvic floor ultrasound. Neurourol Urodyn. 2006; 25(5):424-7.

33. Hundley AF, Wu JM, Visco AG. A comparison of perineometer to brink score for assessment of pelvic floor muscle strength. Am J Obstet Gynecol. 2005; 192(5):1583-91

34. Bump RC, Mattiasson A, Bø K, Brubaker LP, DeLancey JO, Klarskov P, et al. The standardization of terminology of female pelvic organ prolapse and pelvic floor dysfunction. Am J Obstet Gynecol. 1996; 175(1):10-7.

35. Bø K, Raastad R, Finckenhagen HB. Does the size of the vaginal probe affect measurement of pelvic floor muscle? Acta Obstet Gynecol Scand. 2005; 84(2):129:33

36. Rahmani N, Mohseni-Bandpei MA. Application of perineometer in the assessment of pelvic floor muscle strength and endurance: a reliability study. J Bodyw Mov Ther. 2011; 15(2):209-14. 